\title{
REQUISITOS TÉCNICOS PARA EL \\ Aseguramiento de la Calidad En la adquisición de elementos y trabajos realizados a las aeronaves de la Fuerza Aérea Colombiana
}

E objetivo de este trabajo es elaborar tecnicamente respaldados, que permitan sentar doctrina para mejorar la selección de los proveedores que suministran servicios en la adquisición o reparación de elementos aeronáuticos que sean aplicados por la Jefatura de Operaciones Logisticas, durante los procesos precontractuales.

Esta idea surgió a raiz de la necesidad de mejorar la calidad de los proveedores con los que contrata la Fuerza Aérea, debido a que en algunas circunstancias se presentan dudas en el proceso de aseguramiento de la calidad de los elementos y servicios adquiridos por la falta de respaldo documental. Entonces, ¿cuenta la Fuerza Aérea Colombiana con normas y requisitos para la adquisición y reparación de elementos aeronáuticos y de aseguramiento de la calidad de los trabajos propuestos para su contratación?. El respaldo teórico de esta investi$\mathrm{ga}$ ción se centra en los

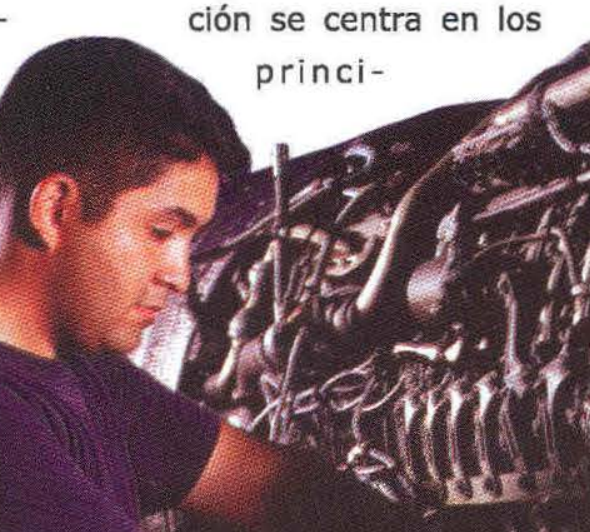


normas que enmarcan el aseguramiento de la calidad para la adquisición o reparación de los elementos aeronáuticos: regulaciones de la organización aeronáutica civil internacional, regulaciones federales de aviación de los Estados Unidos y autoridades de aviación conjunta de la Comunidad Europea, el código de regulaciones federales de los Estados Unidos, reglamentos aeronáuticos de Colombia y el reglamento interno JOL_SEPLA 008 del 16 de marzo de 2003 dónde se encuentran los procedimientos y criterios generales para el desarrollo de la contratación estatal en la agencia de compras de la Fuerza Aérea, en las diferentes etapas precontractual, de celebración, perfeccionamiento y legalización, ejecución y liguidación de los contratos.

En este contexto se aplicó una investigación descriptiva a través de la cual se recolectaron los datos en los departamentos de control de calidad de las empresas de aviación en el ámbito nacional, en la organización de la aviación civil internacional, la administración federal de aviación de los Estados Unidos y demás entidades aeronáuticas nacionales e internacionales.

Tambien, se realizaron entrevistas a los oficiales de la Jefatura de Operaciones Logísticas, quienes plantearon que la opción para que la Fuerza Aérea mejorara la implementación de requisitos para adquirir elementos o contratar reparaciones era seguir las políticas y normas emanadas por la administración federal de aviación de los Estados Unidos o por las autoridades de aviación conjunta de Europa, ya que cuentan con la experiencia y se mantienen en la vanguardia de adelantos en la aviación en el ámbito administrativo. Asímismo, se realizó la comparación de manuales de aseguramiento de calidad en entidades nacionales e internacionales con los procedimentos realizados en la Fuerza Aérea. El análisis de los anteriores documentos evidenció que es necesario complementar los requisitos técnicos que certifiquen el aseguramiento de la calidad en la adquisición o reparaciones aeronáuticas.

Es necesario estandarizar e implementar términos de referencia técnica que lleven a asegurar el servicio que se adquirirá por parte de los proveedores que permitan la calidad del producto.

De tal forma, que la propuesta consiste en entregar los requisitos técnicos minimos para la adquisición de elementos y reparaciones aeronáuticas que son desarrolladas a partir de los documentos requeridos para la

\begin{tabular}{|c|c|}
\hline \multicolumn{2}{|c|}{ IDENTIFICACIÓN GENERAL DEL PROYECTO } \\
\hline PROGRAMA & $\begin{array}{l}\text { ESPECIALIZACIÓN EN LOGÍSTICA } \\
\text { AERONÁUTICA }\end{array}$ \\
\hline TÍTULO & $\begin{array}{l}\text { REQUISITOS TÉCNICOS PARA EL } \\
\text { ASEGURAMIENTO DE LA CALIDAD } \\
\text { EN LA ADQUISICION DE ELEMENTOS } \\
\text { Y TRABAJOS REALIZADOS A LAS } \\
\text { AERONAVES DE LA FUERZA AERREA } \\
\text { COLOMBIANA }\end{array}$ \\
\hline & $\begin{array}{l}\text { CT.DIEGO HERNÁN BEDOYA GIRALDO } \\
\text { CT.DAGOBERTO BLANCO BARRAGÁN } \\
\text { CT.JAIRO ORLANDO ORJELAARÉVALO }\end{array}$ \\
\hline
\end{tabular}

LÍNEA DE

INVESTIGACIÓN LOGÍSTICA

AREA

FUNCIONAL LOGÍSTICA AERONÁUTTCA

GESTOR JEFE DE PLANEACIÓN-JOL

AÑO 2003 adquisición y reparación de elementos aeronáuticos, como el plan de materiales y los componentes nuevos.

También se presentan las definiciones de los documentos requeridos para los diferentes procesos en la adquisición de los materiales aeronáuticos, así como los diferentes tipos de certificados.

Finalmente, al implementar los anteriores requisitos se complementarán las reglamentaciones y se optimizará la adquisición y reparaciones de elementos logrando la calidad de los proveedores, como el cumplimiento de garantias en la contratación. 